\title{
Heart and Heart-Lung Transplantation: Standards and Improvements
}

\author{
Wolfgang Harringer, M.D., Ph.D., Axel Haverich, M.D., Ph.D. \\ Division of Thoracic and Cardiovascular Surgery, Hannover Medical School, Carl-Neuberg-Strasse 1, 30623 Hannover, Germany
}

Published Online: December 24, 2001

\begin{abstract}
Standards and new developments of thoracic organ transplantation are reviewed with particular focus on current treatment strategies, alternatives to transplantation, and xenotransplantation. The current indications for heart, single and bilateral sequential lung, and heart-lung transplantation as well as the technical aspects of each procedure are presented. Criteria for transplant recipients and absolute and relative contraindications are pointed out. Criteria for donor selection are also reviewed. The results of single, double-sequential, and heart-lung transplantation over the past 10 years as reported by the International Society for Heart and Lung Transplantation Database are stated. In addition, the experience of the lung and heart-lung transplantation program at the Hannover Medical School is reviewed, including the current immunosuppression regimens. This experience includes 1075 heart, heart-lung, and lung transplantations since 1983. The 1- and 5-year actuarial survival

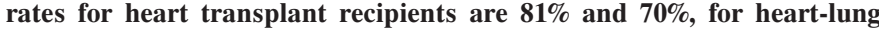
recipients $76 \%$ and $61 \%$, and for single and double lung transplant recipients $77 \%$ and $59 \%$, respectively. During the past decade there has been continuous improvement in the results of heart, lung, and heart-lung transplantation. Alternatives to thoracic organ transplantation, livingrelated lobar transplantation, new antirejection agents, and xenograft transplantation are areas for continuing and future investigation.
\end{abstract}

Thoracic organ transplantation looks back on more than 30 years of clinical experience. It was James Hardy who, on June 11, 1963, performed the first human single lung transplantation following extensive experimental studies on organ preservation, surgical technique, and immunosuppression. One year later he performed the first human heart transplantation utilizing a primate donor organ. Both patients died early, but the border between experimental work and clinical application was crossed. Cardiac transplantation gained some clinical relevance during the 1970s after the pioneering work of Barnard and Shumway, whereas lung transplantation at this time was still not clinically successful. Intensified experimental research and the development of a new immunosuppressive drug (cyclosporin A) was necessary to allow the first successful heart-lung transplantation by Reitz in Stanford in 1981. In 1983 and 1985, Cooper performed the first successful single and double lung transplantations. Tracheal anastomotic complications required modification of the operative technique for double lung transplantation from the en bloc technique to

Correspondence to: W. Harringer, M.D., Ph.D., e-mail: harringer@thg. mh-hannover.de "bilateral sequential," further abandoning the use of extracorporeal circulation in many patients.

During the last two decades, thoracic organ transplantation has changed from a highly experimental surgical procedure to a widely accepted therapeutic option for end-stage cardiac and pulmonary failure. Heart transplantation volume steadily increased worldwide during the 1980s and plateaued since 1990 despite the use of older donor organs. In Germany the scarcity of donor organs has even led to a decrease in cardiac transplantations during the last years [1]. The number of heart-lung transplantations peaked in 1989 and has been declining ever since, paralleling a continuous increase in isolated lung transplantation.

\section{Indications and Recipient Selection}

Improved immunosuppression and antibiotic and antimycotic therapy has led to improved survival and long-term results even in patients with multiple concomitant diseases. However, the limited availability of donor organs, the cost of the procedure, and intensive follow-up care requires careful recipient evaluation and selection. Criteria have evolved over time, are continuously refined, and might differ slightly from center to center based on experience, priorities, and attitudes. They can provide guidelines for recipient selection, but acceptance of a patient as a transplant candidate must be an individual decision involving all members of the transplant team.

Most centers accept patients up to 65 years of age for heart or lung transplantation and up to 50 years for combined heart-lung transplantation. As for other solid organ transplant candidates, there is no lower age limit, albeit the number of transplants in children, especially infants, is low. Adequate compliance with medical therapy and the absence of alcohol or drug abuse remains mandatory for all transplant candidates.

\section{Heart}

Current indications for cardiac transplantation includes patients with end-stage heart failure [New York Heart Association (NYHA) III-IV] and an estimated 1-year survival of $<50 \%$. Most patients suffer from dilative or ischemic cardiomyopathy (Fig. 1). The left ventricular ejection fraction should be $<20 \%$ with a 
HTX
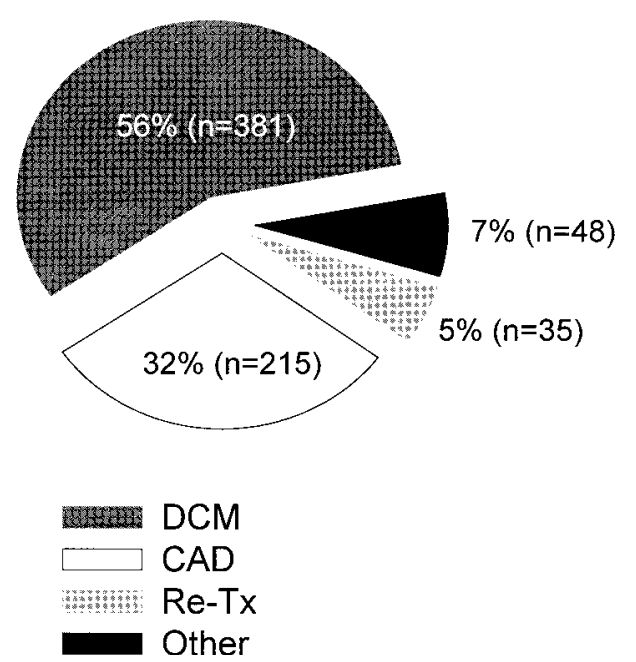

HLTX
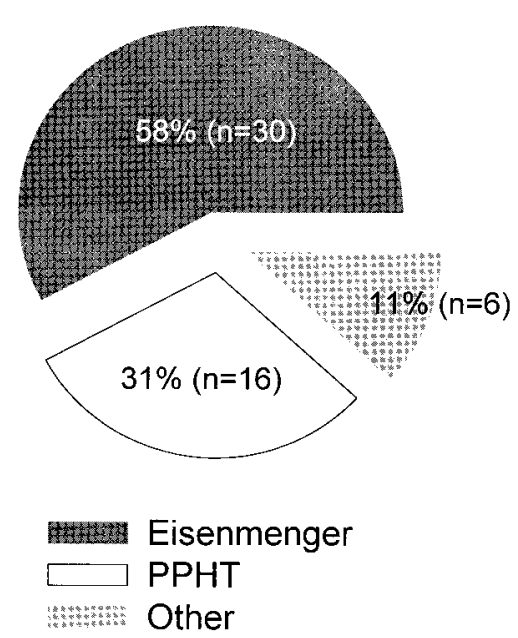

Fig. 1. Indications for heart (HTX) and heart-lung (HLTX) transplants at Hannover Medical School. DCM: dilated cardiomyopathy; CAD: coronary artery disease; Re-Tx: retransplantation; PPHT: primary pulmonary hypertension. cardiac index of $<2 \mathrm{~L} / \mathrm{min} / \mathrm{m}^{2}$ and elevated left ventricular filling pressures. More recently, reduced maximum oxygen consumption $(<14 \mathrm{ml} / \mathrm{kg} / \mathrm{min})$ has been identified as a reliable predictor for poor prognosis in heart failure [2]. Priority should be given to patients with malignant ventricular arrhythmias, active ischemia, right ventricular failure, and hyponatremia.

Extracardiac malignancies, elevated pulmonary arteriolar resistance $\left(>6\right.$ Wood units or $>480 \mathrm{dyn} \cdot \mathrm{s} \cdot \mathrm{cm}^{-5}$ ) despite intensive combined therapy with vasodilator and inotropic agents for several days, irreversible renal or hepatic dysfunction, and severe pulmonary disease $\left(\mathrm{FEV}_{1}<1.5 \mathrm{~L} / \mathrm{s}\right)$ are considered absolute contraindications for heart transplantation. Relative contraindications include acute concomitant diseases (infection, pulmonary emboli, peptic ulcer, cerebral ischemia) and diabetes with significant secondary organ damage.

\section{Lung}

Idiopathic pulmonary fibrosis is currently treated by isolated single lung transplantation. Patients with other interstitial lung diseases (pneumoconiosis, histiocytosis X, sarcoidosis) can also undergo transplantation successfully. A specific problem in patients with sarcoidosis may be the frequent histologic and clinical recurrence of the disease [3]. Internationally, most single lung transplantations $(56 \%)$ are currently performed for chronic obstructive lung disease [4]. We prefer bilateral sequential lung transplantation in most of these patients to avoid problems of overinflating the native lung early postoperatively and infectious complications during follow-up. Chronic bronchial infections, including cystic fibrosis, chronic bronchitis, or bilateral bronchiectases, are best treated with bilateral sequential lung transplantation. Patients with pulmonary vascular disorders, including primary pulmonary hypertension, Eisenmenger syndrome, and pulmonary venoocclusive disease can also be treated successfully with single or (better) bilateral lung transplantation. Concomitant repair of cardiac defects can be carried out simultaneously, thereby avoiding heartlung transplantation [5]. Whether one or two lungs should be transplanted in patients with pulmonary hypertension is still under debate. Single lung transplantation optimizes donor utilization, is technically simple and effective, but carries a higher risk of reperfusion injury. As $90 \%$ of cardiac output is directed toward the transplanted lung, because of its lower vascular resistance a ventilation-perfusion mismatch unequivocally occurs during episodes of transplant dysfunction (reperfusion edema, rejection, infection), which is poorly tolerated. In our program, bilateral sequential lung transplantation is the preferred procedure for these candidates. It offers equal distribution of pulmonary blood flow, less reperfusion edema, and better tolerance of acute and chronic rejection episodes. Pulmonary vascular resistance is decreased extremely effectively, allowing improvement of (even significantly impaired) right ventricular function and achieving excellent symptomatic relief.

For all transplant candidates, end-stage lung disease despite optimal medical therapy, as assessed by interdisciplinary evaluation, is mandatory. Also, organ-preserving surgical procedures should be evaluated as to whether they can be an alternative to transplantation in each individual. Lung volume-reduction surgery and pulmonary thromboendarterectomy represent surgical options for highly selected candidates [6, 7]. Whereas pulmonary thromboendarterectomy is considered the treatment of choice in our program, in patients with pulmonary hypertension due to thromboembolism long-term results of lung volume reduction and clear patient selection criteria are needed to judge the value of this procedure as a lung transplant alternative.

Contraindications for lung transplantation include lifetime-limiting multisystemic disorders, advanced connective tissue diseases, active malignancies, severe right ventricular dysfunction, coronary artery disease, significant left ventricular dysfunction, active extrapulmonary infection, disabling renal and hepatic dysfunction, complicated diabetes mellitus, and smoking within the last 6 months. Preoperatively, steroid treatment should be decreased to the lowest dosage tolerated by the patient, preferably $<20 \mathrm{mg} /$ day. Previous thoracotomies and pleurodeses increase the risk of bleeding during and after transplantation, especially if the use of extracorporeal circulation is necessary for implantation of the donor lung. Computed tomography (CT) scans can be helpful for 
determining the extent of adhesions. Preoperative evidence of multiresistant organisms (e.g., Pseudomonas cepacia) occurs often in patients with cystic fibrosis but is no longer considered a contraindication in our program. Careful evaluation of paranasal sinuses, including eventually surgical correction, and specific postoperative antibiotic treatment is mandatory in these patients. Maximum patient compliance with medical and physical therapy is of utmost importance for a successful outcome, especially during a complicated postoperative course.

\section{Heart-Lung}

Primary pulmonary hypertension with severe right ventricular dysfunction and severe tricuspid insufficiency, right ventricular thrombi, aneurysmal pulmonary arteries, or significantly reduced left ventricular performance as well as Eisenmenger syndrome due to severe congenital cardiac defects represent the current indications for combined heart-lung transplantation. Clinical symptoms of right heart failure alone, however, do not exclude patients from successful isolated lung transplantation. This restricted patient selection is due to a higher early mortality rate of heart-lung recipients and a technically more demanding operation. It furthermore reduces the possibility of a "domino" operation, where the recipient's heart is transplanted into another patient [8].

\section{Donor Criteria}

The discrepancy between increasing waiting lists and donor organ shortage requires extremely careful, fast, safe evaluation of potential organ donors by experienced transplant surgeons. As a result, acceptance criteria for organ donors could be liberalized for heart and lungs in most centers with good results [9, 10]. In general, donors with a history of malignancy (except brain and nonmelanomatous skin cancer) and positive serologies for human immunodeficiency virus (HIV) or hepatitis B and C are not considered suitable, even for a critically ill patient. Prospective crossmatching of heart or lung transplant recipients is required only if preformed panel-reactive antibodies indicate significant presensitization.

\section{Heart}

Currently, hearts from donors up to 60 years of age are regularly accepted, and in selected cases even older donors are considered. Long-term function of old donor hearts is still discussed controversially. Use of inotropes for stabilization of cardiac output poses no contraindication for transplantation. However, high doses of catecholamines can lead to a reduction in $\beta$-receptors on cardiac muscle cells as well as intramyocardial hemorrhage and necrosis. Knowing the amount of drug, duration of use, and central venous pressure of the donor is critical for judging cardiac performance. Chest trauma, resuscitation, long-term pressure support, or brain death itself may cause cardiac dysfunction. Routine echocardiography can provide valuable information for assessment of donor hearts but is not available on a regular basis in many donor hospitals. Careful direct inspection and palpation of coronary arteries or angiography in older organ donors is necessary to assess atherosclerotic changes. Blood group, weight, and height are of importance for matching donor and recipient. Differences
Table 1. Cardiac donor criteria.

\section{Age 1 to $60+$ years}

No history of cardiac disease

No history of severe chest trauma

Adequate cardiac function

Systolic AP $>90 \mathrm{mmHg}$ or mean $\mathrm{AP}>60 \mathrm{mmHg}$

Inotropic support $<10 \mu \mathrm{g} / \mathrm{kg} / \mathrm{min}$ dopamine or dobutamine

CVP 8-10 $\mathrm{mmHg}$

Normal ECG and/or echocardiogram

No prolonged hypotension or hypoxemia

AP: arterial pressure; CVP: central venous pressure; ECG: electrocardiogram.

Table 2. Pulmonary donor criteria.

Age 1 to $55+$ years

No history of pulmonary disease or heavy smoking

Clear chest radiograph

Acceptable lung compliance (Elastance $<20 \mathrm{~cm} \mathrm{H}_{2} \mathrm{O} / \mathrm{L}$ )

Adequate oxygenation $(\mathrm{Pa}) \mathrm{O}_{2} / \mathrm{FiO}_{2} 250-300 \mathrm{mmHg}$ )

No evidence of pulmonary infection or aspiration

Intubation time $<7$ days

of up to $20 \%$ of height are acceptable. In patients with elevated pulmonary resistance $\left(>250 \mathrm{dyn} \cdot \mathrm{s} \cdot \mathrm{cm}^{-5}\right)$ acceptance of smaller hearts should be avoided owing to an increased risk of right heart failure after transplantation. Current criteria for cardiac donors in our center are listed in Table 1. Modern solutions for myocardial preservation (St. Thomas Hospital, Bretschneider, University of Wisconsin) allow total ischemia times of up to 5 hours $[11,12]$.

\section{Lung and Heart-Lung}

Evaluation of the donor history with respect to preexisting lung disease (asthma), smoking, aspiration, and date of intubation provides valuable information about the suitability of lungs. Donor age should be $<55$ years, and the chest radiograph should be clear. Ventilator settings must be optimized (tidal volume 15 $\mathrm{ml} / \mathrm{kg}$, positive end-expiratory pressure $5 \mathrm{~cm} \mathrm{H}_{2} \mathrm{O}$ ) and replacement of fluids restricted [central venous pressure $(\mathrm{CVP})<8$ $\mathrm{mmHg}$. Lung function must be adequate, shown by arterial blood gases at $\mathrm{FiO}_{2}$ of 0.4 and 1.0. Infection must be ruled out by bronchoscopy and (ideally). Gram-staining before lung retrieval. In general, massive purulent secretions and evidence of gramnegative rods or fungus preclude the recovery of lungs in most centers. Sometimes patients with atelectasis can be improved by increasing the tidal volume during donor procurement. We consider bronchoscopy of every lung donor to be mandatory, and it should be carried out by the explanting surgeon to help discriminate between acceptable and unacceptable donor lungs. Our current criteria for pulmonary donors are listed in Table 2. Recipients are selected by blood group and by comparable height and weight. We omitted further chest measurements because with bilateral lung transplantation smaller lungs are well tolerated and oversized lungs can be reduced by multiple atypical resections [13]. Furthermore, many centers have abandoned matching donor and recipients according to their cytomegalovirus (CMV) status to expand the donor pool. Prophylactic administration of ganciclovir or CMV hyperimmune globulin (or both) achieves comparable 
early results, but long-term bronchiolitis obliterans must be evaluated [14].

\section{Operative Technique}

\section{Donor}

Thoracic organs are usually retrieved as part of multiorgan procurement. A median sternotomy is performed (usually by the abdominal team), and most of the abdominal dissections are finished before preparations for heart and lung perfusion are started. The pericardium and both pleurae are opened widely. The superior vena cava is mobilized and encircled by a heavy nonabsorbable suture. The ascending aorta is separated from the pulmonary artery and encircled with umbilical tape. Once the abdominal team is ready, heparin is administered and the ascending aorta is cannulated for cardioplegia delivery. In the case of heart-lung or lung retrieval, the main stem of the pulmonary artery is also cannulated. When abdominal and thoracic retrieval teams are ready, the superior vena cava is ligated, and the inferior vena cava and right inferior pulmonary vein are incised to allow optimal drainage of both ventricles. After aortic cross-clamping, cold cardioplegia [Hannover: $4000 \mathrm{ml}$ Bretschneider's HTK-solution (Custodiol; Dr. F. Köhler Chemie; Alsbach, Germany) at $\left.4^{\circ} \mathrm{C}\right]$ is delivered via the ascending aorta. Following perfusion, cardiectomy is performed by division of the inferior vena cava, left and right pulmonary veins, pulmonary artery, aorta, and superior vena cava. For the lung or heart-lung donor, cold high-volume/ low-pressure perfusion [Hannover: $3500 \mathrm{ml}$ low potassium-dextrane (LPD) solution (Perfadex; Vitrolife; Uppsala, Sweden) with tris buffer added to achieve a $\mathrm{pH}$ of 7.5] is carried out via the pulmonary artery with continued ventilation. Additionally, $500 \mu \mathrm{g}$ of prostacyclin is injected intravenously before perfusion. The left heart is decompressed by amputating the left atrial appendage instead of incising the right pulmonary vein. The heart-lung block is then mobilized after resecting the pericardium and opening both pleural spaces. The trachea is dissected, the lungs are completely inflated, and the trachea is closed with a stapling device and divided between staple lines. For retrieval of lungs alone, heart and lungs are generally separated in situ with great care to create large enough atrial cuffs around the pulmonary veins and sufficient length of pulmonary arteries for implantation. Organs are then triple-bagged in cold HTK (heart) or LPD (lungs and heart-lungs) solution and stored on ice for transportation. This allows ischemia times up to 5 hours for the heart and 6 to 8 hours for the lungs.

\section{Recipient}

Heart or combined heart-lung transplantation is performed via a median sternotomy utilizing extracorporeal circulation. Following aortic and bicaval cannulation the aorta is cross-clamped, and a cardiectomy is carried out with small right and left atrial cuffs. For cardiac replacement only, the donor heart is then implanted starting with the anastomoses of donor and recipient left atrium and continuing with the right atrium, pulmonary artery, and aorta according to the technique described by Lower and Shumway. Some centers, recently including ourselves, prefer selective anastomoses of the inferior and superior vena cava for better preservation of right atrial geometry to decrease the incidence of atrial arrhythmias [15]. Heterotopic heart transplantations are performed rarely in some centers for patients with pulmonary hypertension and small donor hearts [16].

In heart-lung recipients, right and left pneumonectomies are carried out with utmost care to avoid injury to the vagal and phrenic nerves. The tracheal bifurcation is then dissected and divided just above the carina. Generally, extensive collaterals are present and require careful control of bleeding in the posterior mediastinum. En bloc implantation of donor organs is then carried out with anastomoses between the donor and recipient trachea, right atrium, and aorta. Timing of the operation is crucial because explantation of recipient organs can be difficult and timeconsuming owing to extensive adhesions if one or more cardiac operations were performed previously.

Single lung transplantation is performed via a posterolateral thoracotomy through the fourth intercostal space for patients with restrictive pulmonary disease and the fifth intercostal space for those with obstructive pulmonary disease. The superior and inferior pulmonary veins, pulmonary artery, and main stem bronchus are dissected. Heparin (100 units/kg) is administered, the lung is collapsed, and the pulmonary artery is clamped to judge any compromise in the patient's hemodynamics and oxygenation during the following pneumonectomy. If cardiopulmonary bypass is required, it can be carried out by intrathoracic (right atriumaorta) or inguinal (femoral artery-femoral vein) cannulation. Pulmonary veins are then ligated and divided; and the respective lung is removed after division of the pulmonary artery and the bronchus just proximal to the upper lobe branches. The pericardium is then opened between the phrenic nerve and hilum; and the incision is extended circumferentially to expose the left atrium at the junction of the pulmonary veins. One or two cartilages of the bronchus are removed, avoiding extensive dissection to ensure a good blood supply. The donor bronchus is shortened up to one cartilage proximal to the upper lobe to ensure sufficient blood supply from pulmonary artery collaterals.

Lung implantation is then performed starting with the bronchial anastomosis (PDS sutures: membranous part 4/0, continuous technique; cartilaginous part $3 / 0$, interrupted technique). Then donor and recipient pulmonary arteries are anastomosed (5/0 running Prolene suture), and the donor left atrial cuff is connected to the recipient's left atrium (4/0 continuous Prolene suture), isolated by an angled side-biting clamp. For the anastomoses, bilateral sequential lung replacement is performed technically identical, starting usually with the right side. The chest is entered, however, via a bilateral anterior thoracotomy in the fourth interspace with transection of the sternum and ligation of the internal mammary vessels. Recently, a video-assisted minimally invasive approach through bilateral anterolateral thoracotomies without ligation of internal mammary arteries has been used in most of our patients, avoiding complications of sternal transection. A special challenge for the right-sided graft occurs during the subsequent left-sided pneumonectomy when the transplanted lung overflows with the full cardiac output following hours of ischemia.

After the operation the double-lumen tube is replaced by a single-lumen nasopharyngeal tube. The patient is then bronchoscoped to remove secretions from the lungs and to examine the anastomoses. 


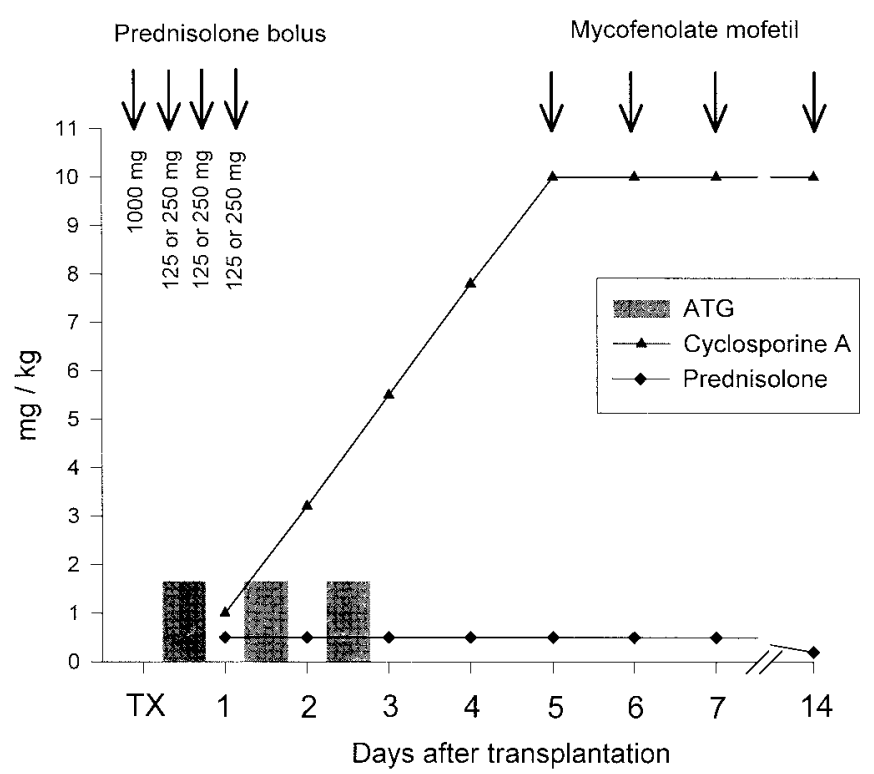

Fig. 2. Current standard immunosuppression protocol for heart, heartlung, and lung transplant recipients. Differences between heart and lung transplants with regard to steroid dose and induction therapy are outlined in the text.

\section{Immunosuppression}

Today most centers use a triple-drug immunosuppression regimen (cyclosporin A, prednisolone, azathioprine) following thoracic organ transplantation. Additionally, induction therapy is applied with polyclonal or monoclonal antibodies (e.g., ATG, OKT3) and pulsed steroids starting immediately postoperatively. Our immunosuppressive protocol following both heart and lung allografting is shown in Figure 2. We currently replace azathioprine with mycofenolate mofetil in our routine immunosuppression protocol for both heart and lungs, starting with $2 \times 500 \mathrm{mg} /$ day on postoperative day (POD) 5 and increasing up to $3 \times 1000 \mathrm{mg}$ within the following 2 weeks. In contrast to heart transplantation, we have discontinued induction therapy in patients receiving lung transplants. Intravenous cyclosporin A is usually administered within 6 hours postoperatively. The initial dose $(1 \mathrm{mg} / \mathrm{kg})$ is increased within the following 1 to 2 weeks up to $10 \mathrm{mg} / \mathrm{kg}$, depending on renal and hepatic function. Cyclosporin A serum levels (monoclonal assay) should range between 220 and 300 $\mathrm{ng} / \mathrm{ml}$ for the first year with a reduction to 150 to $200 \mathrm{ng} / \mathrm{ml}$ for the following years. Patients also receive azathioprine 1 to $2 \mathrm{mg} / \mathrm{kg}$ with a target white blood cell count of 4000 cells $/ \mathrm{mm}^{3}$ or higher. Prednisolone (1000 mg IV) is administered intraoperatively followed by three doses of $125 \mathrm{mg}$ (heart) or $250 \mathrm{mg}$ (lung and heart-lung) at 12-hour intervals. Prednisolone maintenance therapy is started on POD 2 (initially $0.5 \mathrm{mg} / \mathrm{kg}$ and tapered to 0.07 $\mathrm{mg} / \mathrm{kg}$ within 1 year). Cardiac rejection is generally diagnosed by transvenous endomyocardial biopsies. Noninvasive diagnosis of myocardial function with echocardiography, however, gains increased importance, especially beyond the first postoperative year. In our center, standard monitoring of patients with an uncomplicated course after 2 years is done by echocardiography alone, with transvenous biopsies being performed only during routine coronary angiography once a year.
Severe rejection episodes including myocyte necrosis are treated with pulsed steroids (prednisolone $1000 \mathrm{mg}$ /day for 3 days) with rebiopsy after 7 to 14 days. Steroid-resistant rejection or rejection with hemodynamic compromise is treated more aggressively, using monoclonal or polyclonal antibodies.

The diagnosis of pulmonary allograft rejection is challenging because the clinical signs may resemble those of infection and preservation injury. Fever, leukocytosis, cough, increased sputum production, rapidly developing pulmonary infiltrates, and pulmonary decompensation are nonspecific signs and symptoms of rejection. Infection must be ruled out by bronchoscopy and bronchoalveolar lavage. Transbronchial biopsy is used in some centers to allow a histologic diagnosis of rejection. Severe rejection episodes may require mechanical ventilation and even extracorporeal membrane oxygenation during treatment. Combined heart-lung grafts more often undergo isolated rejection of the lungs than combined cardiac and pulmonary rejection. Thus one cannot rely on myocardial biopsies to diagnose lung rejection. Treatment of pulmonary rejection episodes follows a regimen comparable to that of cardiac rejection. Posttransplantation obstructive pulmonary function or obliterative bronchiolitis poses a major problem for heart-lung or lung transplant recipients. It is assumed that it indicates "chronic rejection" and is treated by augmented or modified immunosuppression. Additionally, pulmonary infections may play a role as a trigger mechanism [17].

\section{Results}

\section{International Data}

Heart transplantation volume peaked during the mid-1990s and declined since, with 3500 to 4000 procedures performed every year as recorded in the International Society for Heart and Lung Transplantation (ISHLT) database. Overall, the international 1-year survival rate is $80 \%$ with a following constant mortality rate of $4 \%$ per year. Interestingly, no significant survival improvement has occurred when comparing patients given transplants during 1988-1992 and those during 1992-1997. Increasing donor and recipient age as well as expanding indications during these time intervals might have some influence on survival statistics.

In 2000 a total of 104 heart-lung transplantations and 1412 isolated lung transplantations (single lung 673, double lung 739) were reported to the ISHLT database. Heart-lung transplantation peaked in 1989, plateaued, and declined significantly during recent years despite a continuous rise in donor age. The 1-year survival rate is $60 \%$, with an 11 -year survival rate around $25 \%$. A substantial number of early deaths are caused by unspecific graft failure and hemorrhage, whereas infection and bronchiolitis obliterans are the principal cause of death after the first year. Lung transplantation has increased rapidly since 1989, but growth seems to be plateauing during the last 3 years. The 1 -year survival is approximately $70 \%$ and the 4-year survival around $50 \%$. Variations occur depending on the diagnosis, with the best results in emphysema and cystic fibrosis patients and the worst in patients with primary pulmonary hypertension [18]. Recent analysis of the ISHLT database begins to demonstrate a survival benefit after 5 years for patients receiving double lung transplants compared to the single lung group. 
Table 3. Thoracic transplantations at Hannover Medical School: July 1983 to December 2000.

\begin{tabular}{lll}
\hline Organ & Total no. & Retransplantation (no.) \\
\hline Heart & 679 & 35 \\
Heart-lung & 52 & 12 \\
Single lung & 120 & 20 \\
Double lung & 224 & \\
\hline
\end{tabular}

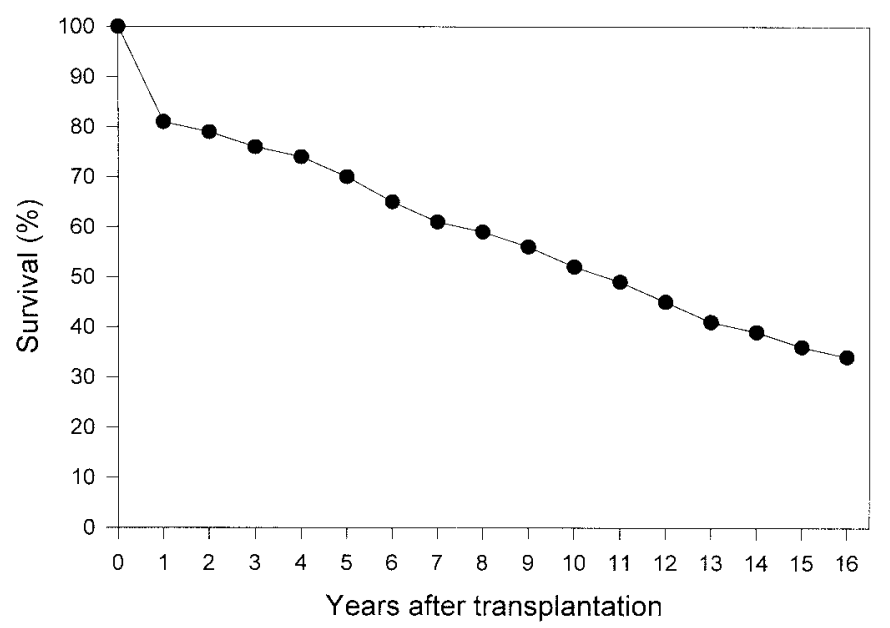

Fig. 3. Actuarial survival curve for heart transplants at Hannover Medical School.

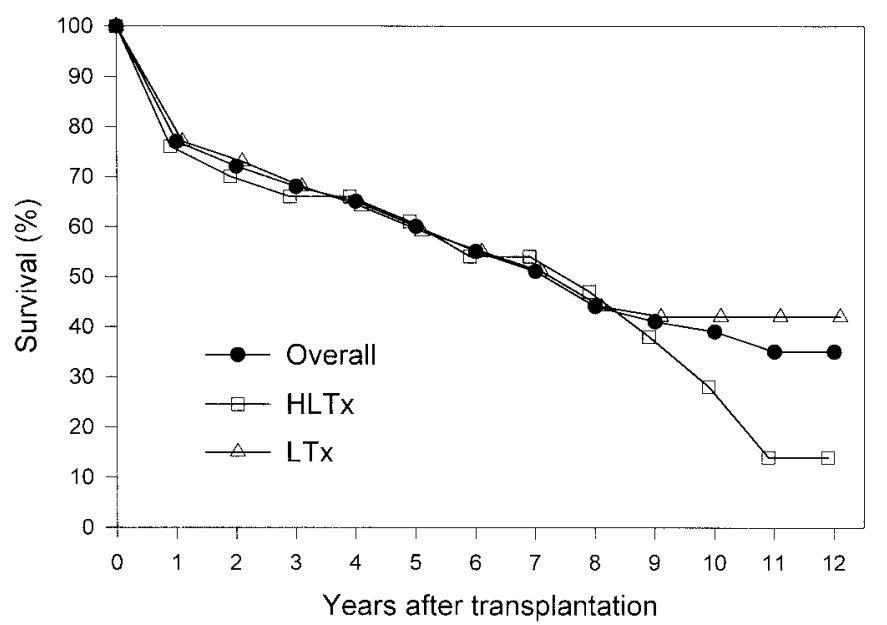

Fig. 4. Actuarial survival curve for heart-lung (HLTx) and isolated lung (LTx) transplants at Hannover Medical School.

\section{Hannover Data}

Starting with heart transplantation in July 1983, a continuously growing thoracic organ transplantation program was developed at Hannover Medical School with a total of 1075 heart, heart-lung, and lung transplantations performed until December 31, 2000 (Table 3). Survival curves for different transplantations are demonstrated in Figures 3 and 4. Indications for transplantation are outlined in Figures 1 and 5.

\section{New Developments}

\section{Clinical Advances}

Organ donor shortage and a continuing increase in the number of patients on waiting lists for heart transplantation account for the $20 \%$ to $30 \%$ mortality during the pretransplantation period. Continuous improvement of mechanical assist devices has led to successful bridging of patients to cardiac transplantation over extensive time periods ( $>300$ days), but bleeding complications, infections, renal failure, and embolic events still pose a major threat to these potential candidates [19]. By contrast, improvements in organ perfusion and venous stasis allows successful recovery of already damaged organs (e.g., liver, kidneys) in these patients. Furthermore, improved hemodynamics allow mobilization and rehabilitation of the patients with substantial improvement of their physical abilities. A decrease in the size and an increase in the reliability of assist devices has even permitted hospital discharge of patients awaiting cardiac transplantation. Meanwhile, permanently implantable left ventricular (LV) assist devices are considered by some to be an alternative to transplantation rather than a bridge in highly selected patients [20]; and initial trials with new devices are currently being undertaken.

Five years ago a new surgical alternative for patients with end-stage heart failure and dilated left ventricles was reported [21]. Initial results of LV reduction plasty sounded promising, but whether this procedure can be a true alternative to cardiac transplantation remains doubtful. Currently, less-invasive treatment options targeting LV geometry (Acorn CSD, Myosplint) are being intensively studied. Additionally, biventricular pacing and mitral valve reconstruction as well as high risk coronary revascularization belong to the modern armamentarium of treatment options in selected patients with severely impaired LV function. The most significant alleviation of symptoms and increased survival of patients with end-stage heart failure has resulted from improved medical strategies.

Whereas adult cardiac transplantation looks back on 30 years of history, the first successful replacement in an infant was performed more than a decade ago by Bailey in Loma Linda, California. Although neonates and infants represent a growing group of pediatric heart transplant recipients, survival remains inferior to that in older children. Indications in the neonatal age group are dominated by noncorrectable congenital defects, whereas in the older age group dilative cardiomyopathy represents the main reason for heart transplantation. Hypoplastic left heart syndrome as an indication for neonatal transplantation is still under discussion. The results of alternative palliative surgical correction of this malformation, the "Norwood" procedure, are improving; and deaths are fewer while on the waiting list $[22,23]$. Neonates can develop partial immunotolerance owing to the underdeveloped immune system, requiring less immunosuppression. Additionally, the incidence of chronic rejection seems to be less compared to that of adult patients. Functional results are excellent, but true long-term experience in this age group is still limited.

Donor organ shortage in children awaiting lung transplantation stimulated Starnes and coworkers to utilize living related donor organs. Two donors, mainly father and mother, donate one lower lobe each (one right and one left) for bilateral sequential transplantation. So far, 37 patients with cystic fibrosis, among them 10 children, have undergone this operation. The 1-year survival is 
DLTX

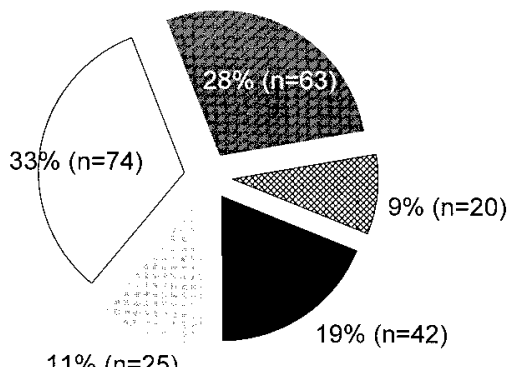

$11 \%(n=25)$

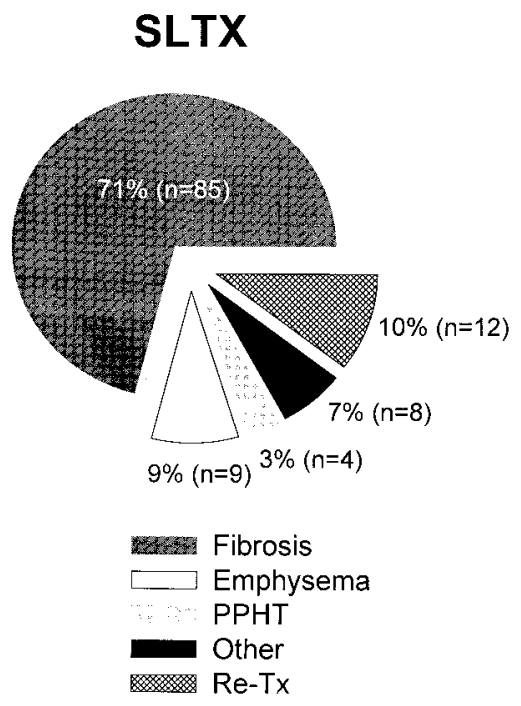

Fig. 5. Indications for bilateral sequential (DLTX) and single (SLTX) lung transplant at Hannover Medical School.
$71 \%$, and functional results are reported to be good [24]. Alternatively, splitting donor lungs has been introduced by a group in Paris, France into clinical practice. This technique allows division of a single lung into two lobes, thereby increasing the number of available organs for small recipients [25].

Another challenging question related to lung transplantation is whether to perform retransplantation in patients who develop early graft failure or severe obliterative bronchiolitis. Despite significant improvement of survival rates over the past 3 years, the overall 1-year survival is $50 \%$ for retransplantations compared to $70 \%$ for first-time transplants $[3,26]$. Careful selection of patients allows 1-year survival rates above $70 \%$, indicating that retransplantation might be a reasonable procedure [27].

\section{Experimental Advances}

More immunosuppressive drugs than ever before have progressed from experimental laboratory work to clinical testing. The general advantage of these new drugs is apparently more specific suppression of the immune system. Cyclosporin G, IMM 125 (both cyclosporin A analogs), and FK 506 block cytokine synthesis and selective $\mathrm{T}$ cell proliferation. Inhibition of both cytokine synthesis and growth factors, including their effects on $\mathrm{T}$ and $\mathrm{B}$ cells, is the mechanism of action for rapamycin and leflunomide. Mycofenolic acid and brequinar sodium, as well as leflunomide, have been shown to reduce purine and pyrimidine synthesis, blocking (relatively selectively) DNA synthesis of T and B cells. Differentiation of $\mathrm{T}$ and $\mathrm{B}$ cells to fully immunocompetent cells is inhibited by brequinar sodium and desoxyspergualine via a yet unknown mechanism. Results of preclinical studies suggest that a combination of these new drugs will be significantly more effective, more specific, and therefore less toxic for kidneys and bone marrow than the currently used immunosuppression regimens [28]. Another new therapeutic approach is blocking adhesion molecules, which mediate vascular endothelial interaction and infiltration of immunocompetent cells. Anti-ICAM-1 and anti-LFA-1 antibodies have been demonstrated to induce specific immunotolerance in a mouse heart transplant model. This effect seems to be speciesrelated; but antibody administration combined with low, subthera- peutic doses of cyclosporin A in rats also seem to achieve effective immunosuppression. These results correlate well with first experiences in human kidney transplant recipients. Administration of an oligosaccharide (Sialyl-Lewis X) binding to p-selectin seems to be effective in prophylaxis of rejection and reperfusion in a rat lung transplantation model [29]. The ease of administration and low toxicity renders the potential clinical application of such oligosaccharides attractive for potential clinical use.

A potential solution for closing the gap between increasing waiting lists and donor organ shortage is transplantation of xenogenic grafts. Ready availability and comparable size favor the pig as an ideal organ donor, but transplantation of pig organs into humans or primates leads to hyperacute rejection with destruction of the transplanted organ. Increased immunosuppression that suppresses these acute rejection episodes leads to life-threatening infections. Additionally, ethical issues and the risk of virus transmission across species barriers have delayed the move from "bench to bedside" despite significant experimental advances in this field. These approaches or successful induction of (xenogenic) donor-specific tolerance may well hope to increase the potential donor pool for patients with end-stage heart or lung disease requiring organ replacement. Whether this "natural" approach or the widespread biotechnologic advances in the field of artificial organs and tissue engineering will ultimately supplement or replace human allografts for transplantation remains to be seen. Until then, we are challenged to improve our results after "conventional" organ transplantation, especially in the field of chronic rejection and true long-term results.

Résumé. Les techniques standards et les développements récents en matière de transplantation d'organes intrathoraciques sont passés en revue avec une perspective particulière sur les stratégies modernes, les alternatives à la transplantation, et la xénotransplantation. Les indications actuelles de la transplantation cardiaque, du poumon uni- et bilatérale ainsi que de la transplantation cour-poumon ainsi que les aspects techniques de chaque procédé sont présentés. En ce qui concerne les receveurs, les critères de transplantation ainsi que les contreindications relatives et absolues sont soulignées. Les critères utilisés pour la sélection des donneurs sont également passés en revue. Les résultats de la transplantation uni et bilatérale, séquentielle, et la transplantation 
cour-poumon, enregistrés pendant ces dix dernières années par la banque des données de la Société Internationale de Transplantation Cardiaque et Poumons sont exposés. L'expérience du programme de transplantation du poumon et du cour-poumons de l'école de Médecine de Hanovre, y compris les régimes d'immunosuppression couramment employés, sont présentés. Cette expérience comprend 1075 transplantations du cœur, du cœur-poumon et du poumon réalisées depuis 1983. Les taux de survie actuarielle à 1 et à 5 ans chez les patients receveurs de transplantation cardiaque sont, respectivement, de $81 \%$ et de $70 \%$, pour la transplantation cour-poumon, de $76 \%$ et de $61 \%$ et pour la transplantation du poumon uni- et bilatérale, de $77 \%$ et de $59 \%$. Pendant la dernière décennie, on a assisté à des améliorations continues en matière de transplantation cardiaque, du poumon et du cœur-poumon. Les alternatives à la transplantation des organes thoraciques, les transplantations lobaires provenant des donneurs vivants, les nouveaux agents antirejet et la transplantation de xénogreffes sont des domaines d'investigation présentes et futures.

Resumen. En este artículo se revisan los estándares y los nuevos desarrollos del trasplante de órganos torácicos con enfoque especial en las estrategias terapéuticas, las alternativas al trasplante y el xenotrasplante. Se presentan las indicaciones actuales para el trasplante de corazón, el trasplante único y bilateral secuencial de pulmón y el trasplante de corazón-pulmón, así como los aspectos técnicos de cada procedimiento, destacando los criterios de contraindicaciones absolutas y relativas, junto con una revisión de los criterios para la selección de donantes. Se informan los resultados de los trasplantes único y secuencial de pulmón y de corazón y de corazón-pulmón en los últimos 10 años, según los reportes de la Society for Heart and Lung Transplantation Database. También se informa la experiencia del programa de trasplante de corazón-pulmón de la Escuela de Medicina de Hannover, incluyendo los actuales regímenes de inmunosupresión. Esta experiencia incluye 1075 trasplantes de corazón, corazón-pulmón y pulmón desde 1983. Las tasas de supervivencia actuarial a uno y cinco años de los pacientes trasplantados de corazón son $81 \%$ y $70 \%$, de corazón-pulmón $76 \%$ y $61 \%$, y de pulmón único y doble $77 \%$ y 59 , respectivamente. En el curso de la última década se ha logrado continuada mejoría en los resultados del trasplante de corazón, corazón-pulmón y pulmón. Las alternativas al trasplante de órganos torácicos, el trasplante lobular de donantes vivos, el desarrollo de nuevos agentes anti-rechazo y el xenotrasplante son campos de importante investigación futura.

\section{References}

1. Smit, H., Schoeppe, W., Zickgraf, T.: Organspende und Transplantation in Deutschland. Neu-Isenburg, Deutsche Stiftung Organtransplantation, 1996, pp. 23-26

2. Mancini, D.M., Eisen, H., Kussmaul, W., Mull, R., Edmunds, L.H., Jr., Wilson, J.R.: Value of peak exercise oxygen consumption for optimal timing of cardiac transplantation in ambulatory patients with heart failure. Circulation 83:778, 1991

3. Müller, C., Briegel, J., Haller, M., Vogelmeier, C., Bittman, I., Welz, A., Fürst, H., Dienemann, H.: Sarcoidosis recurrence following lung transplantation. Transplantation 61:1117, 1996

4. Hosenpud, J.D., Bennett, L.E., Keck, B.M., Boucek, M.M., Novick, R.J.: The registry of the International Society for Heart and Lung Transplantation: seventeenth official report-2000. J. Heart Lung Transplant. 19:909, 2000

5. Aeba, R., Griffith, B.P., Hardesty, R.L., Kormos, R.L., Armitage, J.M.: Isolated lung transplantation for patients with Eisenmenger's syndrome. Circulation (Suppl. II) 88:452, 1993

6. Jamieson, S.W., Auger, W.R., Fedullo, P.F., Channick, R.N., Kriett, J.M., Tarazi, R.Y., Moser, K.M.: Experience and results with 150 pulmonary thromboendarterectomy operations over a 29-month period. J. Thorac. Cardiovasc. Surg. 106:116, 1993

7. Cooper, J.D., Patterson, G.A., Sundaresan, R.S., Trulock, E.P., Yusen, R.D., Pohl, M.S., Lefrak, S.S.: Results of 150 consecutive bilateral lung volume reduction procedures in patients with severe emphysema. J. Thorac. Cardiovasc. Surg. 112:1319, 1996

8. Madden, B.P., Hodson, M.E., Tsang, V., Radley-Smith, R., Khaghani, A., Yacoub, M.Y.: Intermediate-term results of heart-lung transplantation for cystic fibrosis. Lancet 339:1583, 1992
9. El Oakley, R.M., Yonan, N.A., Simpson, B.M., Deiraniya, A.K.: Extended criteria for cardiac allograft donors: a consensus study. J. Heart Lung Transplant. 15:255, 1996

10. Sundaresan, S., Semenkovich, J., Ochoa, L., Richardson, G., Trulock, E.P., Cooper, J.D., Patterson, G.A.: Successful outcome of lung transplantation is not compromised by the use of marginal donor lungs. $\mathrm{J}$. Thorac. Cardiovasc. Surg. 109:1075, 1995

11. Demertzis, S., Wippermann, J., Schaper, J., Wahlers, T., Schäfers, H.J., Wagenbreth, I., Hausen, B., Haverich, A.: University of Wisconsin versus St. Thomas' Hospital solution for human donor heart preservation. Ann. Thorac. Surg. 55:1131, 1993

12. Briganti, E.M., Bergin, P.J., Rosenfeldt, F.L., Esmore, D.S., Rabinov, M.: Successful long-term outcome with prolonged ischemic time cardiac allografts. J. Heart Lung Transplant. 14:840, 1995

13. Wisser, W., Klepetko, W., Wekerle, T., Laufer, G., Stift, A., Hiesmayr, M., Schlick, W.: Tailoring of the lung to overcome size disparities in lung transplantation. J. Heart Lung Transplant. 15:239, 1996

14. Zamora, M.R., Fullerton, D.A., Campbell, D.N., Leone, S., Diercks, M.J., Fisher, J.H., Badesch, D.B., Grover, F.L.: Use of cytomegalovirus (CMV) hyperimmune globulin for prevention of CMV disease in CMV-seropositive lung transplant recipients. Transplant. Proc. (Suppl. 1) 26:49, 1994

15. Brandt, M., Harringer, W., Hirt, S.W., Walluscheck, K.P., Cremer, J., Sievers, H.H., Haverich, A.: Influence of bicaval anastomoses on late occurrence of atrial arrhythmia after heart transplantation. Ann. Thorac. Surg. 64:70, 1997

16. Khaghani, A., Santini, F., Dyke, C.M., Onuzu, O., Radley-Smith, R., Yacoub, M.H.: Heterotopic cardiac transplantation in infants and children. J. Thorac. Cardiovasc. Surg. 113:1042, 1997

17. Hohlfeld, J., Niedermeyer, J., Hamm, H., Schäfers, H.J., Wagner, T.O.F., Fabel, H.: Seasonal onset of bronchiolitis obliterans syndrome in lung transplant recipients. J. Heart Lung Transplant. 15:888, 1996

18. Harringer, W., Wiebe, K., Strüber, M., Franke, U., Niedermeyer, J., Fabel, H., Haverich, A.: Lung-transplantation: 10 year experience. Eur. J. Cardiothorac. Surg. 16:546, 1999

19. Quaini, E., Pavie, A., Chieco, S., Mambrito, B.: The concerted action "heart" European registry on clinical application of mechanical circulatory support systems: bridge to transplant; the registry scientific committee. Eur. J. Cardiothorac. Surg. 11:182, 1997

20. McCarthy, P.M., Young, J.B., Smedira, N.G., Hobbs, R.E., Vargo, R.L., Starling, R.C.: Permanent mechanical circulatory support with an implantable left ventricular assist device. Ann. Thorac. Surg. 63:1458, 1997

21. Batista, R.J., Santos, J.L., Takeshita, N., Bocchino, L., Lima, P.N., Cunha, M.A.: Partial left ventriculectomy to improve left ventricular function in end-stage heart disease. J. Card. Surg. 11:96, 1996

22. Bove, E.L., Lloyd, T.R.: Staged reconstruction for hypoplastic left heart syndrome: contemporary results. Ann. Surg. 224:387, 1996

23. Razzouk, A.J., Chinnock, R.E., Gundry, S.R., Johnston, J.K., Larsen, R.L., Baum, M.F., Mulla, N.F., Bailey, L.L.: Transplantation as a primary treatment for hypoplastic left heart syndrome: intermediateterm results. Ann. Thorac. Surg. 62:1, 1996

24. Starnes, V.A., Barr, M.L., Cohen, R.G., Hagen, J.A., Wells, W.J., Horn, M.V., Schenkel, F.A.: Living-donor lobar lung transplantation experience: intermediate results. J. Thorac. Cardiovasc. Surg. 112:1284, 1996

25. Couetil, J.P., Tolan, M.J., Loulmet, D.F., Guinvarch, A., Chevalier, P.G., Achkar, A., Birmbaum, P., Carpentier, A.F.: Pulmonary bipartitioning and lobar transplantation: a new approach to donor organ shortage. J. Thorac. Cardiovasc. Surg. 113:529, 1997

26. Novick, R.J., Schäfers, H.J., Stitt, L., Andréassian, B., Klepetko, W., Hardesty, R.L., Frost, A., Patterson, G.A.: Seventy-two pulmonary retransplantations for obliterative bronchiolitis: predictors of survival. Ann. Thorac. Surg. 60:111, 1995

27. Schäfers, H.J., Hausen, B., Wahlers, T., Fieguth, H.G., Jurmann, M., Borst, H.G.: Retransplantation of the lung: a single center experience. Eur. J. Cardiothorac. Surg. 9:291, 1995

28. Hausen, B., Morris, R.E.: Review of immunosuppression for lung transplantation: novel drugs, new uses for conventional immunosuppressants, and alternative strategies. Clin. Chest Med. 18:353, 1997

29. Brandt, M., Boeke, K., Phillips, M.L., Steinhoff, G., Haverich, A.: Effect of oligosaccharides on rejection and reperfusion injury after lung transplantation. J. Heart Lung Transplant. 16:352, 1997 